\title{
Evaluasi Pelaksanaan dan Manfaat Rencana Pengamanan Air Minum (RPAM) Operator di PDAM Kota Payakumbuh
}

\author{
BELINDA PRAGA ${ }^{1}$, RACHMAWATI S.DJ ${ }^{1}$ \\ 1. Jurusan Teknik Lingkungan, Fakultas Teknik Sipil dan Perencanaan Institut \\ Teknologi Nasional (ITENAS) Bandung \\ Email : belindapraga01@gmail.com
}

\begin{abstract}
ABSTRAK
PDAM Kota Payakumbuh diharapkan dapat mengalirkan air minum yang aman bagi masyarakat. Hal tersebut mengaCu pada target RPJMN 2015-2019; dimana pada tahun 2019 harus tercapai 100\% akses air minum yang aman dilihat dari aspek 4K. Diperlukan suatu upaya untuk dapat mengamankan air minum, mulai dari sumber air baku hingga pelanggan. Program Kementerian PUPR, yakni RPAM dapat menjadi solusi untuk mengamankan air minum dari sumber hingga pelanggan melalui pendekatan analisis dan manajemen risiko.Evaluasi RPAM dilakukan untuk mengetahui capaian pemenuhan aspek 4K; sehingga dapat diketahui apakah upaya tindakan pengendalian yang dilakukan telah berjalan efektif atau belum; dengan begitu selanjutnya dapat dilakukan rekomendasi terkait upaya yang dapat diterapkan untuk meningkatkan capaian pemenuhan aspek 4K. Capaian pemenuhan aspek 4K tahun 2013- 2016 belum terpenuhi. Hal tersebut dikarenakan masih terdapat tindakan pengendalian yang belum berjalan efektif dalam menangani kejadian bahaya dan risiko yang terjadi.
\end{abstract}

Kata kunci: RPAM, PDAM Kota Payakumbuh, Aspek 4K

\begin{abstract}
PDAM Payakumbuh expected to deliver safe drinking water for the community. This refers to the target RPJMN 2015-2019; where in 2019 must reach 100\% access to safe drinking water viewed from $4 K$ aspect. Therefore, an effort is needed to secure drinking water, from raw water sources to customers. Government programs issued through the PUPR Ministry, namely RPAM can be a solution to secure drinking water from source to customer through a risk analysis and management approach. Evaluation of RPAM implementation is done to know the achievement of 4K aspect; so it can be seen whether the efforts of the control measures carried out have been effective or not; with subsequent recommendations can be made related to what efforts can be applied to improve the achievement of $4 \mathrm{~K}$ aspects. The achievement of $4 K$ aspect in 2013-2015 has not been fulfilled. This is because there are still control measures that have not been effective in dealing with hazard events and risks that occur.
\end{abstract}

Keywords: RPAM, PDAM Payakumbuh, Aspects $4 K$ 


\section{PENDAhUluan}

Perusahaan Daerah Air Minum (PDAM) Kota Payakumbuh merupakan perusahaan daerah yang menyediakan pelayanan kebutuhan air minum di wilayah Kota Payakumbuh. Air baku yang digunakan berasal dari 3 (tiga) mata air, yaitu Batang Tabik, Sungai Dareh, dan Sikamaruncing. Pada tahun 2016, cakupan pelayanan PDAM Kota Payakumbuh telah mencapai $99,11 \%$ untuk wilayah Kota Payakumbuh dan $1,15 \%$ untuk pelayanan di Kabupaten Limapuluh Kota (wilayah perbatasan). Wilayah pelayanan PDAM Kota Payakumbuh terdiri dari 5 (lima) kecamatan, yaitu Kecamatan Payakumbuh Utara, Kecamatan Payakumbuh Barat, Kecamatan Payakumbuh Timur, Kecamatan Payakumbuh Selatan, dan Kecamatan Lamposi Tigo Nagori (Latina) dengan total jumlah penduduk sebanyak 129.404 jiwa (PDAM Kota Payakumbuh, 2016).

Kebutuhan air minum di wilayah pelayanan PDAM Kota Payakumbuh akan terus meningkat seiring dengan bertambahnya jumlah penduduk di wilayah tersebut. Apabila mengacu pada target yang tercantum dalam Rencana Pembangunan Jangka Menengah Nasional (RPJMN) 2015-2019; dimana pada tahun 2019 ditargetkan seluruh warga negara Indonesia memperoleh $100 \%$ akses air minum yang aman, yakni air minum yang berkualitas dan menyehatkan, maka untuk dapat mencapai target RPJMN 2015-2019 tersebut, diperlukan suatu upaya pengamanan pelayanan air minum. Salah satu upaya yang dapat dilakukan ialah dengan menerapkan Rencana Pengamanan Air Minum (RPAM) yang diadopsi dari konsep yang dikembangkan oleh World Health Organization (WHO), yaitu Water Safety Plan (WSP) (Departemen PU Cipta Karya, 2012).

RPAM dapat didefinisikan sebagai upaya pengamanan pasokan air minum, dimulai dari sumber air hingga pelanggan, dengan mempertimbangkan aspek 4K, yaitu kualitas (K1), kuantitas (K2), kontinuitas (K3), dan keterjangkauan (K4) yang dilakukan secara terpadu oleh berbagai pihak (salah satunya adalah PDAM) menggunakan pendekatan analisis dan manajemen risiko. Menurut Direktorat Jendral Cipta Karya Kementerian PU (2012), dalam pelaksanaannya, RPAM terbagi menjadi 3 (tiga) komponen, yaitu RPAM Sumber, RPAM Operator, dan RPAM Konsumen. PDAM Kota Payakumbuh mulai melaksanakan RPAM Operator pada tahun 2013. Pelaksanaan RPAM Operator dilakukan PDAM Kota Payakumbuh sebagai upaya pencegahan serta pengendalian kejadian bahaya dan risiko yang dapat terjadi di daerah sumber air baku (mata air) hingga wilayah distribusi (pelanggan). Jika PDAM Kota Payakumbuh dapat melaksanakan RPAM Operator dengan baik, maka PDAM Kota Payakumbuh akan memperoleh manfaat (benefit) apabila ditinjau dari aspek 4K (kualitas, kuantitas, kontinuitas, dan keterjangkauan). Oleh karena itu, untuk mengetahui bagaimana pencapaian aspek $4 \mathrm{~K}$ dan besarnya nilai manfaat dari pelaksanaan RPAM di PDAM Kota Payakumbuh, maka dalam penelitian ini dilakukan suatu evaluasi terhadap pelaksanaan dan manfaat RPAM tersebut.

\section{METODOLOGI}

Metodologi penelitian menjelaskan beberapa tahapan pada penelitian, seperti studi pustaka, pengumpulan data, serta metode yang akan digunakan untuk pengolahan dan analisis data.

\subsection{Studi Pustaka}

Studi pustaka merupakan cara yang digunakan untuk memperoleh data, informasi tertulis atau teori yang berkaitan dengan topik yang dikaji. Hal tersebut dapat dijadikan acuan untuk melakukan pembahasan dan pemecahan suatu masalah dalam suatu penelitian. Studi pustaka dapat diperoleh dari berbagai sumber, seperti jurnal, buku, dokumentasi, internet dan pustaka. 


\subsection{Pengumpulan Data}

Pengumpulan data pada penelitian ini meliputi pengumpulan data primer dan sekunder.

\section{a. Data Primer}

Pengumpulan data primer dilakukan dengan melakukan wawancara dan observasi langsung di lapangan. Data primer yang dikumpulkan ialah berupa data tekanan di jalur distribusi terjauh (critical point) dan bukti pelaksanaan RPAM, yakni berupa dokumentasi di lokasi timbulnya kejadian bahaya dan risiko.

\section{b. Data Sekunder}

Data sekunder diperoleh dari studi pustaka terkait teori dan peraturan yang berhubungan dengan Sistem Penyediaan Air Minum (SPAM) dan RPAM, serta database dari PDAM Kota Payakumbuh berupa dokumen RPAM, data bukti pelaksanaan dan data produksi.

\subsection{Pengolahan dan Analisis Data}

Pengolahan dan analisis data terhadap manfaat RPAM dilakukan untuk mengetahui manfaat yang dapat diperoleh PDAM Kota Payakumbuh dengan dilaksanakannya RPAM Operator apabila ditinjau dari aspek 4K. Data yang diperoleh dari hasil pengumpulan data, selanjutnya direkap dalam Tabel 1. Hasil pengolahan data akan dibuat dalam suatu grafik dan selanjutnya dilakukan analisis secara kualitatif.

Tabel 1. Data Produksi PDAM Kota Payakumbuh

\begin{tabular}{|c|c|c|c|}
\hline No. & Data yang Dibutuhkan & Satuan & Tahun \\
\hline \multicolumn{4}{|l|}{ K1 (Kualitas) } \\
\hline 1 & Harga air minum & $\mathrm{Rp} / \mathrm{m}^{3}$ & $2013-2016$ \\
\hline 2 & Harga air bersih & $\mathrm{Rp} / \mathrm{m}^{3}$ & $2013-2016$ \\
\hline \multicolumn{4}{|l|}{ K2 (Kuantitas) } \\
\hline \multirow[t]{3}{*}{3} & Debit air baku (inlet) & $\mathrm{m}^{3} /$ det & $2013-2016$ \\
\hline & & $\mathrm{m}^{3} / \mathrm{bln}$ & $2013-2016$ \\
\hline & & Rp/bln & $2013-2016$ \\
\hline \multirow[t]{3}{*}{4} & Debit air produksi & $\mathrm{m}^{3} /$ det & $2013-2016$ \\
\hline & & $\mathrm{m}^{3} / \mathrm{bln}$ & $2013-2016$ \\
\hline & & Rp/bln & $2013-2016$ \\
\hline \multirow[t]{3}{*}{5} & Debit air terjual & $\mathrm{m}^{3} /$ det & $2013-2016$ \\
\hline & & $\mathrm{m}^{3} / \mathrm{bln}$ & $2013-2016$ \\
\hline & & Rp/bln & $2013-2016$ \\
\hline \multirow[t]{3}{*}{6} & Kebocoran & $\%$ & $2013-2016$ \\
\hline & & $\mathrm{m}^{3} /$ det & $2013-2016$ \\
\hline & & Rp/bln & $2013-2016$ \\
\hline 7 & Jumlah $\mathrm{KK}^{*}$ yang $<10 \mathrm{~m}^{3} / \mathrm{bln}$ & KK & $2013-2016$ \\
\hline 8 & Jumlah total pelanggan & KK & $2013-2016$ \\
\hline \multicolumn{4}{|l|}{ K3 (Kontinuitas) } \\
\hline 9 & Lama pelayanan & jam/hari & $2013-2016$ \\
\hline 10 & Jumlah KK dengan tekanan $<0,5$ bar & KK & 2016 \\
\hline
\end{tabular}

Sumber : Hasil Analisis, 2018

Keterangan : * Kepala Keluarga

\section{HASIL DAN PEMBAHASAN}

Hasil dan pembahasan ini merupakan penjelasan mengenai hasil pengolahan dataterkaitpencapaian masing-masing aspek 4Kdan manfaat yang diperoleh PDAM Kota 
Payakumbuh dengan dilaksanakannya RPAM.Tabel 2 merupakan tabel yang memuat data produksi PDAM Kota Payakumbuh tahun 2013 - 2016.

Tabel 2. Data Produksi PDAM Kota Payakumbuh

\begin{tabular}{|c|c|c|c|c|c|c|}
\hline \multirow[b]{2}{*}{ No } & \multirow{2}{*}{ Parameter } & \multirow{2}{*}{ Satuan } & \multicolumn{4}{|c|}{ Nilai } \\
\hline & & & 2013 & 2014 & 2015 & 2016 \\
\hline \multirow{3}{*}{ I } & K1 - Kualitas & & & & & \\
\hline & 1 Harga air minum ZAMP* & $\mathrm{Rp} / \mathrm{m}^{3}$ & & & & \\
\hline & 2 Harga air bersih & $\mathrm{Rp} / \mathrm{m}^{3}$ & 1.250 & 1.500 & 1.500 & 1.500 \\
\hline \multirow{12}{*}{ II } & K2-Kuantitas & & & & & \\
\hline & 1 Dohit air holu (inlot) & $\mathrm{m}^{3} / \mathrm{det}$ & 0,27 & 0,28 & 0,28 & 0,29 \\
\hline & Debit alr baku (InIet) & $\mathrm{Rp} / \mathrm{bln}$ & & & & \\
\hline & 2 Debit air produksi & $\mathrm{m}^{3} /$ det & 0,27 & 0,28 & 0,28 & 0,29 \\
\hline & 3 Kohilangan air nrodukci & $\%$ & 0,00 & 0,00 & 0,00 & 0,00 \\
\hline & 3 Kenilangan air produksı & $\mathrm{m}^{3} / \mathrm{det}$ & 0,00 & 0,00 & 0,00 & 0,00 \\
\hline & $4 \quad$ Debit air terjual & $\mathrm{m}^{3} /$ det & 0,19 & 0,20 & 0,21 & 0,21 \\
\hline & & $\%$ & 29,63 & 28,57 & 25,00 & 27,59 \\
\hline & 5 Kebocoran & $\mathrm{m}^{3} /$ det & 0,08 & 0,08 & 0,07 & 0,08 \\
\hline & 6 Jumlah $\mathrm{KK}$ yang $<10 \mathrm{~m}^{3} / \mathrm{bln}$ & KK & 5.050 & 5.609 & 5.893 & 6.947 \\
\hline & Jumlah $\mathrm{KK}$ yang $\geq 10 \mathrm{~m}^{3} / \mathrm{bln}$ & KK & 15.860 & 16.188 & 17.450 & 18.953 \\
\hline & 7 Jumlah total pelanggan & KK & 20.910 & 21.797 & 23.343 & 25.900 \\
\hline \multirow{3}{*}{ III } & K3 - Kontinuitas & & & & & \\
\hline & 1 Lama pelayanan & jam/hari & 24 & 22 & 20 & 20 \\
\hline & $\begin{array}{l}2 \text { Jumlah KK dengan tekanan } \\
<0,5 \text { bar }\end{array}$ & KK & - & - & - & 17.931 \\
\hline \multirow{3}{*}{ IV } & K4 - Keterjangkauan & & & & & \\
\hline & $1 \mathrm{UMK}^{\star \star}$ Payakumbuh & $\mathrm{Rp}$ & 1.350 .000 & 1.490 .000 & 1.615 .000 & 1.892 .500 \\
\hline & $24 \%$ dari UMK & $\mathrm{Rp}$ & 54.000 & 59.600 & 64.600 & 75.700 \\
\hline
\end{tabular}

Sumber : PDAM Kota Payakumbuh, 2017a

Keterangan :

\author{
*Zona Air Minum Prima \\ **Upah Minimum Kabupaten/Kota
}

\title{
3.1 Kualitas (K1)
}

Aspek kualitas (K1) merupakan aspek yang memperhatikan kelayakan air minum untuk dikonsumsi oleh masyarakat, sesuai dengan standar kualitas air minum yang diatur dalam Peraturan Menteri Kesehatan RI No. 492 Tahun 2010 tentang Persyaratan Kualitas Air Minum. Sejak tahun 2009, PDAM Kota Payakumbuh mulai mengembangkan jaringan distribusi Zona Air Minum Prima (ZAMP) secara bertahap yang mencakup 6 (enam) kelurahan. Hingga pada tahun 2014, cakupan wilayah yang terlayani jaringan distribusi ZAMP telah mencapai 20 kelurahan dari total 76 kelurahan yang berada di wilayah pelayanan PDAM Kota Payakumbuh.

Berdasarkan dokumen RPAM PDAM Kota Payakumbuh tahun 2014 dan 2016, kualitas air yang diproduksi pada tahun 2013 - 2016 telah sesuai dengan standar baku mutu yang berlaku. Kualitas air baku dan air produksi harus selalu dijaga agar masyarakat dapat terus memperoleh air minum yang aman; sehingga tidak terjadi gangguan pada kesehatan masyarakat tersebut.Berdasarkan SNI 6775:2008 tentang Tata Cara Pengoperasian dan Pemeliharaan Unit Paket Instalasi Pengolahan Air, sebaiknya pengujian kualitas air baku dan air minum dilakukan secara berkala, yaitu minimal satu bulan sekali. Diperlukan berbagai 
upaya untuk menjaga kualitas air baku dan air produksi. Beberapa upaya yang dilakukan PDAM Kota Payakumbuh untuk mencapai aspek kualitas (K1) tersebut dapat dilihat pada Tabel 3.

Tabel 3. Contoh Tindakan Pengendalian Terkait Aspek Kualitas (K1) Tahun 2013 - 2016

\begin{tabular}{ccccc}
\hline No. & $\begin{array}{c}\text { Kode } \\
\text { Lokasi }\end{array}$ & \multicolumn{1}{c}{ Kejadian Bahaya } & \multicolumn{1}{c}{ Risiko } & \multicolumn{1}{c}{ Tindakan Pengendalian } \\
\hline 1 & MA*2 & $\begin{array}{l}\text { Adanya peternakan } \\
\text { ayam yang posisinya } \\
\text { lebih tinggi dan terlalu } \\
\text { dekat dengan } \\
\text { broncaptering }\end{array}$ & $\begin{array}{l}\text { Sumber mata air } \\
\text { tercemar, kualitas } \\
\text { air terganggu }\end{array}$ & $\begin{array}{l}\text { Pembongkaran kandang } \\
\text { peternakan ayam, dan } \\
\text { mengakuisisi sumber mata air }\end{array}$ \\
\hline 2 & Semua MA & $\begin{array}{l}\text { Pengendapan pada } \\
\text { slang atau pipa } \\
\text { pembubuh kaporit }\end{array}$ & $\begin{array}{l}\text { Pembubuhan } \\
\text { tidak sempurna, } \\
\text { kualitas air } \\
\text { terganggu }\end{array}$ & $\begin{array}{l}\text { Melakukan pengecekan dan } \\
\text { mengganti slang atau pipa } \\
\text { pembubuh secara berkala }\end{array}$ \\
\hline 3 & $\begin{array}{l}\text { Semua } \\
\text { R** }\end{array}$ & $\begin{array}{l}\text { Tutup manhole } \\
\text { mengalami kerusakan }\end{array}$ & $\begin{array}{l}\text { Masukna kotoran } \\
\text { dari luar ke dalam } \\
\text { reservoir }\end{array}$ & $\begin{array}{l}\text { Melakukan perawatan tutup } \\
\text { manhole reservoir secara } \\
\text { berkala }\end{array}$ \\
\hline
\end{tabular}

Sumber : Dokumen RPAM PDAM Kota Payakumbuh, 2016

Keterangan : *Mata Air; $* *$ Reservoir

Jika mengacu pada kualitas air produksi tahun 2013 - 2016 yang telah sesuai dengan standar baku mutu yang berlaku, maka tindakan pengendalian yang dilakukan oleh PDAM Kota Payakumbuh dinilai telah efektif dalam mengendalikan setiap kejadian bahaya dan risiko terkait aspek K1 yang muncul selama jangka waktu tersebut. Namun, untuk mencapai target pelayanan air minum yang aman, maka PDAM Kota Payakumbuh masih perlu mengembangkan jaringan distribusi ZAMP hingga mencakup seluruh wilayah pelayanan PDAM. Terdapat beberapa tahapan yang perlu dilakukan untuk pengembangan ZAMP, diantaranya yaitu pemilihan lokasi ZAMP, membentuk jaringan distribusi yang dapat diisolasi, penyediaan reservoir dan supply air untuk 24 jam/hari, menyediakan fasilitas untuk kemudahan operasi, serta menyediakan fasilitas untuk pengendalian kualitas air. Aspek yang perlu diperhatikan dalam penentuan lokasi ZAMP ialah terkait aspek teknis, sosial, dan manajemen (Haq dan Masduqi, 2014).

\subsection{Kuantitas (K2)}

Aspek kuantitas (K2) ini merupakan aspek yang terkait dengan banyaknya debit air minum yang diterima oleh pelanggan setelah melalui proses pengolahan dan distribusi. Faktor-faktor yang berpengaruh terhadap perhitungan aspek K2, yaitu besarnya persentase kehilangan air pada saat proses produksi, persentase kehilangan air pada distribusi atau Non-Revenue Water (NRW), serta jumlah pelanggan (KK) yang mendapatkan air bersih sebanyak 10 $\mathrm{m}^{3} / \mathrm{KK} /$ bulan.

Berdasarkan literatur dalam Djembarmanah (2016), safety factor dalam proses produksi terdapat pada rentang $5-10 \%$; namun idealnya ialah $<5 \%$. Kehilangan air pada proses produksi di PDAM Kota Payakumbuh pada tahun 2013 hingga 2016 masing-masing telah mencapai 0\% (Tabel 2). Apabila mengacu pada literatur yang digunakan, maka besarnya kehilangan air di PDAM Kota Payakumbuh sudah sesuai dengan kondisi ideal. Semakin besar persentase air yang hilang, maka kuantitas air yang diterima konsumen akan semakin menurun; sehingga pemenuhan kebutuhan air minum masyarakat akan terganggu. Tidak adanya kehilangan air pada tahap produksi, dikarenakan pengolahan yang dilakukan hanya berupa proses desinfeksi di lokasi sumber, yang selanjutnya air minum tersebut langsung didistribusikan ke pelanggan; sehingga tidak ada penggunaan air untuk proses backwash, 
tidak ada pengolahan lumpur, serta tidak ada penggunaan air untuk aktivitas pegawai di lokasi sumber. Agar pengolahan dengan proses desinfeksi berjalan efektif; sehingga dapat menghasilkan air minum dengan kualitas yang baik tanpa memerlukan pengolahan tambahan, maka perlu dilakukan upaya untuk menjaga kualitas agar air baku tetap sesuai dengan baku mutu yang berlaku.

Selain tingkat kehilangan air di tahap produksi yang perlu diturunkan, tingkat kebocoran atau Non Revenue Water (NRW) di jaringan distribusi juga perlu diturunkan hingga 0\%. Hal tersebut mengacu pada prinsip konservasi air dan prinsip RPAM; dimana prinsip RPAM adalah agar masyarakat mendapatkan air minum yang aman; sehingga apabila masih terdapat kehilangan airakibat kebocoran di pipa distribusi, air minum yang mengalir di dalamnya dapat terkontaminasi oleh zat-zat atau kotoran, terutamaEscherichia coli yang dapat menurunkan kualitas air minum tersebut; sehingga konsumen belum mendapatkan air minum yang aman. Selain kualitas air yang terganggu,adanya kehilangan air juga berpengaruh terhadap kuantitas air minum; dimana air minum yang dialirkan ke konsumen akan mengalami penurunan; shingga tidak sesuai dengan jumlah air minum yang seharusnya diterima.

Sama halnya dengan kehilangan air pada tahap produksi, tingkat kehilangan air yang tinggi pada jaringan distribusi pun akan menimbulkan kerugian bagi PDAM dan konsumen. Kerugian bagi PDAM, yaitu berkurangnya air yang dapat terjual ke pelanggandan menurunnya nilai kepuasan pelanggan akibat supply air yang berkurang; sehingga menimbulkan kerugian bagi konsumen tersebut. Oleh karena itu, perlu dilakukan upaya untuk menurunkan tingkat kehilangan air di distribusi hingga 0\%; dimana tingkat kehilangan air di PDAM Kota Payakumbuh pada tahun 2013 hingga 2016 masing-masing sebesar 29,63\%; 28,57\%; 25,00\%; dan 27,59\% (Tabel 2). Masih tingginya persentase kehilangan air di distribusi, disebabkan oleh beberapa faktor, seperti kerusakan jaringan pipa, tidak adanya water meter induk sebagai alat ukur yang akurat, water meter pelanggan yang rusak atau tidak berfungsi, pembacaan water meter yang kurang akurat, dan pencurian air (PDAM Kota Payakumbuh, 2016).

Upaya-upaya yang dapat dilakukan untuk menurunkan tingkat kebocoran hingga $0 \%$ diantaranya adalah mengkalibrasi ketidak akuratan water meter pelanggan, meningkatkan ketelitian dalam membaca water meter, penggantian water meter pelanggan yang rusak, melakukan pendeteksian kebocoran air pada pipa distribusi, dan memperbaiki pipa distribusi yang rusak (Febriany dan Damayanti, 2015). Upaya-upaya tersebut telah dilakukan oleh PDAM Kota Payakumbuh (Tabel 4); sehingga persentase kehilangan air di jaringan distribusi pada tahun 2013 - 2016 relatif menurun walaupun masih tergolong tinggi (Gambar 1).

Tabel 4. Contoh Tindakan Pengendalian Terkait Aspek Kuantitas (K2) Tahun 2013 - 2016

\begin{tabular}{cclll}
\hline No. & $\begin{array}{c}\text { Kode } \\
\text { Lokasi }\end{array}$ & Kejadian Bahaya & \multicolumn{1}{c}{ Risiko } & \multicolumn{1}{c}{ Tindakan Pengendalian } \\
\hline 1 & Semua & $\begin{array}{l}\text { Kebocoran pada pipa } \\
\text { akibat umur pipa yang } \\
\text { sudah tua }\end{array}$ & $\begin{array}{l}\text { Terganggunya } \\
\text { distribusi air, NRW } \\
\text { meningkat }\end{array}$ & $\begin{array}{l}\text { Melakukan perbaikan pada } \\
\text { pipa yang mengalami } \\
\text { kebocoran, mengganti pipa } \\
\text { distribusi dengan kualitas } \\
\text { yang lebih baik }\end{array}$ \\
\hline
\end{tabular}




\begin{tabular}{|c|c|c|c|c|}
\hline No. & $\begin{array}{l}\text { Kode } \\
\text { Lokasi }\end{array}$ & Kejadian Bahaya & Risiko & Tindakan Pengendalian \\
\hline 2 & $\begin{array}{l}\text { Semua } \\
D^{* *}\end{array}$ & $\begin{array}{l}\text { Kebocoran akibat } \\
\text { pelebaran jalan, } \\
\text { pemasangan kabel } \\
\text { Telkom*** dan } \\
\text { PLN**** }\end{array}$ & $\begin{array}{l}\text { Terganggunya } \\
\text { pelayanan, } N R W \\
\text { meningkat }\end{array}$ & $\begin{array}{l}\text { Koordinasi dengan pihak } \\
\text { terkait, melakukan } \\
\text { pengawasan yang intensif } \\
\text { terhadap pelaksanaan } \\
\text { pekerjaan pada jalur pipa } \\
\text { distribusi, dan segera } \\
\text { melakukan perbaikan terhadap } \\
\text { pipa distribusi yang mengalami } \\
\text { kerusakan }\end{array}$ \\
\hline 3 & $\begin{array}{l}\text { Semua } \\
\text { daerah } \\
\text { pelayanan }\end{array}$ & $\begin{array}{l}\text { Kerusakan pada water } \\
\text { meter }\end{array}$ & $\begin{array}{l}\text { Volume atau debit air } \\
\text { distribusi tidak } \\
\text { tercatat, kehilangan } \\
\text { air bertambah }\end{array}$ & $\begin{array}{l}\text { Mengganti water meter yang } \\
\text { rusak dan sudah tidak akurat } \\
\text { lagi }\end{array}$ \\
\hline
\end{tabular}

Sumber : Dokumen RPAM PDAM Kota Payakumbuh, 2016

Keterangan : * Distribusi Utama; ** Distribusi; *** Telekomunikasi; **** Perusahaan Listrik Negara

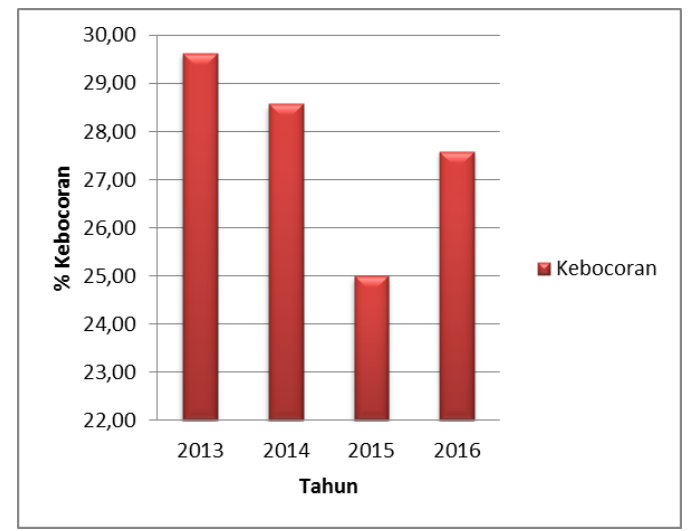

Gambar 1. Grafik Persentase Kehilangan Airdi Jaringan Distribusi Eksisting

(Sumber : PDAM Kota Payakumbuh, 2017a)

Apabila mengacu pada persentase kehilangan air di jaringan distribusi pada tahun 2013 hingga 2016, upaya-upaya yang telah dilakukan PDAM Kota Payakumbuh untuk mengendalikan kehilangan air di distribusi belum sepenuhnya berjalan optimal. Terdapat beberapa hal yang perlu diperhatikan untuk mencapai target keberhasilan dari strategi penurunan kehilangan air di jaringan distribusi, yaitu manajemen tekanan, melakukan tindakan pengendalian kebocoran secara aktif, manajemen jaringan pipa, serta melakukan perbaikan secara cepat dan berkualitas tinggi (Sya'bani, 2016).

Strategi yang dapat diterapkan untuk menangani kehilangan air ialah dengan melakukan pembagian suatu jaringan distribusi air menjadi zona-zona terisolasi. Strategi tersebut merupakan konsep District Meter Area (DMA); dimana dengan menerapkan konsep tersebut dapat mempermudah PDAM untuk memantau kondisi jaringan distribusi. Pembagian zonazona tersebut dapat bersifat sementara atau permanen, serta dari masing-masing zona yang dibentuk dapat dibagi lagi menjadi beberapa sub zona; dimana hal tersebut bertujuan untuk memantau keadaan jaringan distribusi secara lebih detail; sehingga dapat memudahkan pengendalian kehilangan air.Terdapat beberapa hal yang perlu diperhatikan dalam penentuan batas zona distribusi, yaitu ukuran zona, batas zona, sambungan pelanggan dalam zona, elevasi zona, aspek perpipaan, dan jenis konsumen dalam masing-masing zona (Sya'bani, 2016). 
Selain terkait dengan kehilangan air, aspek kuantitas pada RPAM juga terkait dengan banyaknya jumlah air yang dianggap dapat mencukupi kebutuhan air minimum masyarakat; dimana hal tersebut sesuaidengan kebutuhan pokok minimal, yakni 60 liter/orang/hari atau $10 \mathrm{~m}^{3} / \mathrm{KK} /$ bulan berdasarkan Peraturan Menteri Pekerjaan UmumRepublik Indonesia Nomor : 01/PRT/M/2014 tentang Standar Pelayanan Minimal Bidang Pekerjaan Umum dan Penataan Ruang. Di PDAM Kota Payakumbuh, pelanggan yang terlayani belum $100 \%$ mendapatkan air minum sebanyak $10 \mathrm{~m}^{3} / \mathrm{KK} /$ bulan (Tabel 2). Upaya yang dapat dilakukan untuk meningkatkan cakupan pelayanan dan kuantitas air minum yang dialirkan ke konsumen, diantaranya adalah dengan melakukan pengembangan jaringan pelayanan, mengendalikan persentase kehilangan air, serta meningkatkan jam pelayanan menjadi 24 jam/hari. Apabila PDAM Kota Payakumbuh mampu melayani $100 \%$ pelanggannya dengan debit 10 $\mathrm{m}^{3} / \mathrm{KK} /$ bulan, maka kebutuhan minimal masyarakat dapat terpenuhi; sehingga akan ikut pula meningkatkan kepuasan pelanggan dan pendapatan PDAM dari penjualan air minum dapat mengalami peningkatan.

\subsection{Kontinuitas (K3)}

Aspek kontinuitas (K3)merupakan acuan tidak terputusnya aliran air dari instalasi pengolahan air minum (IPAM) kepelanggan. K3 memberikan jaminan pengaliran selama 24 jam per hari; dimana hal tersebut sesuai dengan Peraturan Pemerintah Republik Indonesia No. 122 Tahun 2015 tentang Sistem Penyediaan Air Minum dan Peraturan Menteri Pekerjaan Umum dan Perumahan Rakyat Nomor 27/PRT/M/2016 tentang Penyelenggaraan Sistem Penyediaan Air Minum; dan tekanan air minum di pipa distribusi sebesar 0,5 - 1,0 atm di titik pelayanan kritis atau titik jangkauan pelayanan terjauh seperti yang tercantum dalam Lampiran III Peraturan Menteri Pekerjaan Umum dan Perumahan Rakyat No. 27/PRT/M/2016.

Lama pelayanan di PDAM Kota Payakumbuh pada tahun 2013 hingga 2016 secara berturutturut ialah 24 jam, 22 jam, 20 jam, dan 20 jam (Gambar 2). Pada tahun 2014 hingga 2016, lama pelayanan di PDAM Kota Payakumbuh terus mengalami penurunan sampai 20 jam. Hal tersebut belum sesuai dengan lama pelayanan yang diatur dalam PP RI No. 122 Tahun 2015; sehingga lama pelayanan PDAM Kota Payakumbuh perlu ditingkatkan hingga 24 jam/hari agar masyarakat dapat memperoleh pasokan air minum tanpa terputus. Lama pelayanan < 24 jam disebabkan oleh pasokan listrik dari PLN tidak stabil, belum tersedianya genset sebagai alat pembangkit listrik cadangan, dan adanya gangguan pada motor pompa (PDAM Kota Payakumbuh, 2017b). Tindakan pengendalian yang dilakukan untuk mengatasi kejadian bahaya dan risiko terkait aspek K3 dapat dilihat pada Tabel 5.

Tabel 5. Contoh Tindakan Pengendalian Terkait Aspek Kontinuitas (K3) Tahun 2013 2016

\begin{tabular}{ccccc}
\hline No. & $\begin{array}{c}\text { Kode } \\
\text { Lokasi }\end{array}$ & Kejadian Bahaya & \multicolumn{1}{c}{ Risiko } & Tindakan Pengendalian \\
\hline 1 & Semua P* & Listrik PLN tidak stabil & $\begin{array}{l}\text { Motor pompa dan } \\
\text { panel rusak, } \\
\text { pelayanan } \\
\text { terganggu }\end{array}$ & $\begin{array}{l}\text { Melakukan koordinasi dengan } \\
\text { pihak PLN, dan memastikan } \\
\text { pasokan listrik PLN }\end{array}$ \\
\hline 2 Semua P & $\begin{array}{l}\text { Pengoperasian pompa } \\
\text { kurang maksimal karena } \\
\text { umur pompa yang sudah } \\
\text { tua }\end{array}$ & $\begin{array}{l}\text { Jam pelayanan } \\
\text { terganggu }\end{array}$ & $\begin{array}{l}\text { Selalu dilakukan perawatan } \\
\text { berkala dan mencadangkan } \\
\text { pompa baru }\end{array}$ \\
\hline
\end{tabular}




\begin{tabular}{ccccc}
\hline No. & $\begin{array}{c}\text { Kode } \\
\text { Lokasi }\end{array}$ & Kejadian Bahaya & \multicolumn{1}{c}{ Risiko } & Tindakan Pengendalian \\
\hline 3 & $\begin{array}{l}\text { Semua } \\
\text { SR** }\end{array}$ & $\begin{array}{l}\text { Kebocoran pada pipa } \\
\text { dinas }\end{array}$ & $\begin{array}{l}\text { Jam pelayanan dan } \\
\text { distribusi air } \\
\text { terganggu }\end{array}$ & $\begin{array}{l}\text { Melakukan perbaikan pipa } \\
\text { yang mengalami kebocoran, } \\
\text { meningkatkan mutu pipa dinas } \\
\text { dengan kualitas yang lebih } \\
\text { baik }\end{array}$ \\
\hline
\end{tabular}

Sumber : Dokumen RPAM PDAM Kota Payakumbuh, 2016

Keterangan : *Pompa; **Sambungan Rumah

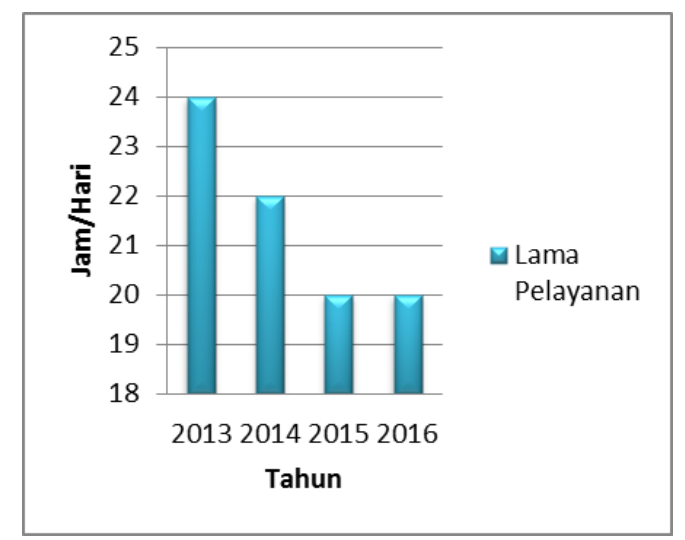

Gambar 2. Grafik Lama Pelayanan PDAMKota Payakumbuh

(Sumber : PDAM Kota Payakumbuh, 2017a)

Apabila melihat jam pelayanan pada tahun 2013 - 2016 yang mengalami penurunan hingga 20 jam/hari, maka tindakan pengendalian yang telah dilakukan PDAM terkait dengan aspek K3 ini belum berjalan secara optimal. Hal tersebut sesuai dengan data yang tercantum dalam dokumen RPAM PDAM Kota Payakumbuh tahun 2014 dan 2016; dimana dalam dokumen tersebut disebutkan bahwa tindakan pengendalian belum berjalan efektif dan belum sepenuhnya dilakukan. Oleh karena itu, pihak PDAM perlu melakukan kaji ulang terhadap kejadian bahaya, risiko, dan rencana perbaikan baik yang sudah berjalan ataupun belum.

Selain jam pelayanan, perlu diperhatikan pula besarnya tekanan air minum di pipa distribusi di titik kritis (critical point) atau titik pelayanan terjauh. Pada tahun 2016, jumlah pelanggan PDAM Kota Payakumbuh dengan tekanan air minum < 0,5 atm adalah sebanyak $17.931 \mathrm{KK}$ atau sekitar 69,23\% dari total pelanggan; sehingga dapat diketahui bahwa sebagian besar tekanan air minum di pipa distribusi PDAM Kota Payakumbuh belum sesuai dengan kriteria yang diatur dalam Peraturan Menteri PUPR No. 27/PRT/M/2016. Nilai tekanan di pipa distribusi dapat dipengaruhi oleh beberapa faktor, seperti debit, usia pipa yang berhubungan dengan koefisien kekasaran pipa, diameter pipa, dan jarak atau panjang pipa. Salah satu faktor yang menyebabkan rendahnya tekanan di pipa distribusi ialah kebocoran pipa; dimana semakin tinggi tingkat kebocoran, maka nilai tekanan akan semakin menurun. Hal tersebut sesuai dengan kondisi eksisting; dimana pada tahun 2016 tingkat kebocoran di distribusi masih tinggi, yakni 27,59\% dan nilai tekanan di titik kritis sebagian besar berada di bawah standar yang berlaku.

Upaya yang telah dilakukan oleh PDAM Kota Payakumbuh untuk mengatasi krisis tekanan tersebut ialah dengan memasang booster pump. Penentuan batas nilai tekanan air di pipa distribusi dimaksudkan, agar air minum dapat sampai ke pelanggan dengan tekanan yang 
cukup; sehingga kuantitas air yang diterima pelanggan dapat memenuhi kebutuhan air yang dipersyaratkan (Agustina, 2007).

\subsection{Keterjangkauan (K4)}

Aspek keterjangkauan (K4) ini merupakan aspek terkaitpenetapan tarif air minum yang layak untuk masyarakat. Tarif air yang ditetapkan oleh PDAM Kota Payakumbuh telah sesuai dengan peraturan yang berlaku, yaitu Peraturan Menteri Dalam Negeri No. 71 Tahun 2016 tentang Perhitungan dan Penetapan Tarif Air Minum; dimana tarif yang ditetapkan tidak boleh melampaui 4\% UMK (Tabel 2). Namun, saat ini PDAM Kota Payakumbuh belum menetapkan tarif yang berbeda antara air bersih dan air minum (ZAMP). Perbedaan tarif air bersih dan tarif air minum tersebut berkaitan dengan perbedaan kualitas air bersih dengan air minum; dimana kualitas air bersih yang sampai ke konsumen belum dapat langsung dikonsumsi, karena kualitasnya belum sesuai dengan baku mutu dalam Peraturan Menteri Kesehatan RI No. 492 Tahun 2010, sedangkan kualitas air minum telah memenuhi standar baku mutu tersebut.Penetapan tarif air minum yang lebih tinggi dari tarif air bersih tidak dapat diputuskan sepihak oleh PDAM, melainkan terdapat beberapa tahapan dalam penentuan tarif tersebut, seperti melakukan koordinasi dengan badan eksekutif, badan legislatif, serta melakukan konsultasi publik atau sosialisasi terhadap masyarakat pengguna jasa PDAM.

Pada Gambar 3 dapat dilihat perbedaan antara tarif air bersih dan tarif air minum. Tarif air maksimum diperoleh dengan cara membagi antara nilai 4\% UMK (Tabel 2) dengan nilai standar pelayanan minimal, yakni $10 \mathrm{~m}^{3} / \mathrm{KK} /$ bulan; sehingga diperoleh tarif air maksimum untuk per meter kubik air yang dapat terjangkau oleh konsumen PDAM. Sedangkan untuk tarif air minum (Gambar 3) tersebut merupakan nilai median antara tarif air bersih eksisting dengan tarif air minum maksimum. Penentuan tarif air minum dengan nilai median tersebut bertujuan agar kenaikan tarif air minum dari tarif air bersih eksisting tidak terlampau tinggi. Jika langsung menerapkan tarif air minum maksimum, dikhawatirkan kenaikan tarif tersebut akan sulit diterima oleh konsumen PDAM.

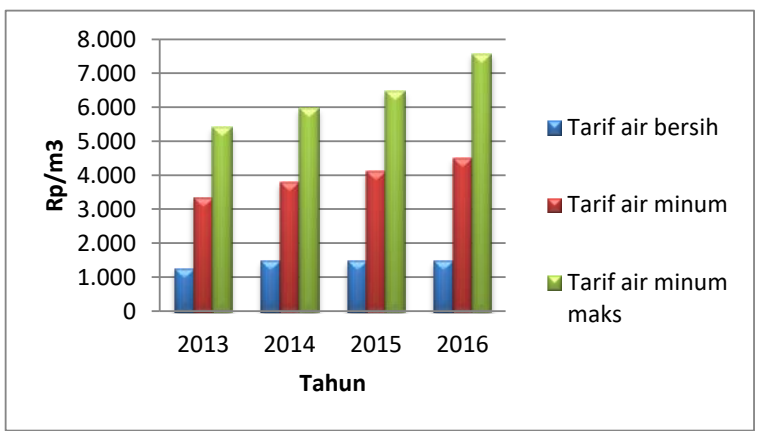

Gambar 3. Grafik Perbedaan Tarif Air (Sumber: Hasil Perhitungan, 2018)

\section{KESIMPULAN}

Evaluasi pelaksanaan RPAM dilakukan untuk mengetahui capaian pemenuhan aspek 4K setelah melaksanakan RPAM Operator. Mengacu pada dokumen RPAM PDAM Kota Payakumbuh tahun 2014 dan 2016, serta data produksi eksisting pada tahun 2013 hingga 2016, beberapa tindakan pengendalian yang telah dilakukan untuk menangani kejadian bahaya dan risiko terhadap $4 \mathrm{~K}$ yang terjadi belum berjalan secara efektif. Hal tersebut menyebabkan pemenuhan aspek 4K selama 2013 - 2016 belum tercapai. PDAM Kota Payakumbuh perlu melakukan tindakan koreksi terhadap tindakan pengendalian yang telah 
dilakukan untuk mengetahui efektivitas tindakan pengendalian tersebut dalam mengatasi kejadian bahaya, serta PDAM Kota Payakumbuh juga perlu melakukan upaya tindak pengendalian lainnya guna dapat menangani kejadian bahaya dan risiko secara tepat dan efektif; sehingga pemenuhan aspek 4K dapat tercapai, serta PDAM dan masyarakat dapat memperoleh manfaat dari pelaksanaan RPAM.

\section{UCAPAN TERIMA KASIH}

Penulis mengucapkan terima kasih kepada PDAM Kota Payakumbuh yang telah mengizinkan penulis untuk melakukan penelitian di PDAM Kota Payakumbuh, dan juga telah berkenan untuk memberikan data yang terkait dengan penelitian.

\section{DAFTAR RUJUKAN}

Agustina, Dian Vitta. (2007). Analisa Kinerja Sistem Distribusi Air Bersih PDAM Kecamatan Banyumanik di Perumnas Banyumanik (Studi Kasus Perumnas Banyumanik Kel. Srondol Wetan). Teknik Sipil UNDIP. Semarang.

Departemen PU Cipta Karya. (2012). Manual Rencana Pengamanan Air Minum (RPAM)Operator.

Febriany, I.E., dan Damayanti, Alia. (2015). Strategi Mengatasi Kebocoran Distribusi Air Bersih di PDAM Menang Kota Mataram. Teknik Lingkungan ITS. Surabaya.

Haq, Bariqul, dan Ali Masduqi. (2014). Sistem Distribusi Air Siap Minum PDAM Kota Malang : Studi Kasus Kecamatan Blimbing. Institut Teknologi Sepuluh November (ITS) : Surabaya.

PDAM Kota Payakumbuh. (2016). Profil PDAM Kota Payakumbuh.

PDAM Kota Payakumbuh. (2017a). Data Produksi dan Distribusi PDAM Kota Payakumbuh Tahun 2013, 2014, 2015, dan 2016.

PDAM Kota Payakumbuh. (2017b). Dokumen RPAM PDAM Kota Payakumbuh Tahun 2014 dan 2016.

Peraturan Menteri Dalam Negeri No. 71 Tahun 2016 tentang Perhitungan dan Penetapan Tarif Air Minum.

Peraturan Menteri Kesehatan RI No. 492 Tahun 2010 tentang Persyaratan Kualitas Air Minum

Peraturan Menteri Pekerjaan Umum No. 01 Tahun 2014 tentang Standar Pelayanan Minimal Bidang Pekerjaan Umum dan Penataan Ruang.

Peraturan Menteri Pekerjaan Umum dan Perumahan Rakyat No. 27 Tahun 2016 tentang Penyelenggaraan Sistem Penyediaan Air Minum.

Peraturan Pemerintah Republik Indonesia No. 122 Tahun 2015 tentang Sistem Penyediaan Air Minum.

Standar Nasional Indonesia (SNI) 6775 Tahun 2008 tentang Tata Cara Pengoperasian dan Pemeliharaan Unit Paket Instalasi Pengolahan Air

Sugihhartati, Dj,R., (2016). Desain Pengolahan Fisika - Kimia I. Teknik Lingkungan ITENAS. Bandung.

Sya'bani, Muhammad R., (2016). Penerapan Jaringan Distribusi Sistem District Meter Area (DMA) dalam Optimalisasi Penurunan Kehilangan Air Fisik Ditinjau dari Aspek Teknis dan Finansial (Studi Kasus : Wilayah Layanan IPA Bengkuring PDAM Tirta Kencana Kota Samarinda). Institut Teknologi Bandung: Bandung. 